\title{
POLÍTICAS DE INTEGRAÇÃO CURRICULAR PARA O ENSINO MÉDIO NO BRASIL CONTEMPORÂNEO: UM ESTUDO NO PROGRAMA ENSINO MÉDIO INOVADOR
}

\author{
HIGH SCHOOL CURRICULUM INTEGRATION POLICIES IN CONTEMPORARY BRAZIL: \\ A STUDY OF THE INNOVATIVE HIGH SCHOOL PROGRAM
}

\author{
POLÍTICAS DE INTEGRACIÓN CURRICULAR PARA LA EDUCACIÓN SECUNDARIA EN \\ BRASIL CONTEMPORÁNEO: \\ UN ESTUDIO EN EL PROGRAMA EDUCACIÓN SECUNDARIA INNOVADORA
}

\begin{abstract}
RESUMO: O presente estudo inscreve-se no campo dos Estudos Curriculares e propõe-se a examinar as políticas de integração curricular para o Ensino Médio produzidas contemporaneamente no Brasil. Para tanto, considera como foco analítico o programa Ensino Médio Inovador, recentemente implementado, dimensionando as concepções de conhecimento escolar emergentes em sua pauta política. Metodologicamente, optou-se pela realização de uma análise documental de diferentes textos curriculares. Ao final, conclui-se que as estratégias políticas que perfazem a constituição da gramática curricular do programa examinado sugerem que o Ensino Médio seja posicionado como um espaço de formação de personalidades produtivas e direcionado para formas curriculares que estimulem o protagonismo dos jovens.
\end{abstract}

PALAVRAS-CHAVE: Integração curricular. Ensino Médio. Brasil.

\begin{abstract}
This study in the field of Curriculum Studies aims to assess High School curriculum integration policies that have been contemporarily produced in Brazil. The analysis is focused on the recently implemented Innovative High School Program and addresses the conceptions of school knowledge that have emerged from its political agenda. The documental analysis of different curriculum texts has been our methodological choice. We have concluded that the political strategies constituting the curriculum grammar of the program here considered suggest the positioning of High School as a place of formation of productive personalities by means of curricula that encourage youths' protagonism.
\end{abstract}

KEYWORDS: Curriculum integration. High School. Brazil.

RESUMEN: Este estudio es parte del campo de los estudios curriculares y se propone examinar las políticas de integración curricular de la escuela media que actualmente se producen en Brasil. Por lo tanto, considera que el enfoque analítico programa Escuela Innovadora, recientemente implementado, dimensionar el conocimiento emergente de los conceptos en su agenda política. Metodológicamente, se decidió realizar un análisis documental de los diferentes textos curriculares. Finalmente, se concluye que las estrategias políticas que conforman la constitución del programa examinados sugieren que la secundaria se posiciona como un área de formación de personalidades productivas y dirigida a formas curriculares que fomenten la participación activa de los jóvenes.

PALABRAS CLAVE: Integración curricular. Escuela Secundaria. Brasil.

\footnotetext{
${ }^{1}$ Doutor em Educação pela Universidade do Vale do Rio dos Sinos. Professor da Universidade de Caxias do Sul, Caxias do Sul, RS - Brasil. E-mail: robertoddsilva@ yahoo.com.br.

Recebido em: 04/05/2015 - Aprovado em: 03/07/2015.
}

\begin{tabular}{l|l|l|l|l|l|l|} 
(C) ETD - Educ. temat. digit. & Campinas, SP & v.17 & n. 2 & p.252-270 & maio/ago. 2015 & ISSN 1676-2592
\end{tabular} 


\section{PALAVRAS INICIAIS}

Recentemente, uma questão colocada em uma prova de Filosofia, no Ensino Médio, causou uma grande polêmica em todo o País. Em uma escola pública de Taguatinga, no Distrito Federal, o professor Antônio Kubitschek trouxe para o contexto de avaliação de sua disciplina trechos de uma música popular - muito conhecida de seus alunos - interpretada pela funkeira Valeska Popozuda. Maior polêmica ainda foi desenvolvida pelo fato de o professor de Filosofia classificar a artista como uma "grande pensadora contemporânea". Para além das condições culturais que perfazem a questão, exploradas exaustivamente pela mídia nos últimos meses, tomamos o referido acontecimento como ponto de partida para a reflexão que desenvolveremos neste texto. Examinaremos a questão de outro modo, distanciando-nos das polêmicas desenvolvidas e problematizando-a em suas condições de possibilidade. Que significados estamos atribuindo aos processos de integração curricular? Quais critérios estamos utilizando para a seleção de nossos conhecimentos a serem ensinados? Que significa uma escola de Ensino Médio atraente, inovadora e flexível?

A busca por formas curriculares alternativas para o Ensino Médio tem se constituído como um dos aspectos mais centrais nas escolas contemporâneas de nosso País. Existe uma espécie de consenso que nos interpela a pensar que os jovens veem as instituições escolares como defasadas, pouco atraentes e onde não desenvolvem suas potencialidades formativas. De certa forma, nossa sociedade tende a reconhecer a necessidade de fabricação de outros currículos escolares para o Ensino Médio mais adequados aos interesses juvenis, aos anseios sociais ou às demandas do mercado de trabalho. Entretanto, a mobilização desse tipo de entendimento, marcado por modalidades específicas de desenvolvimento e de integração curriculares, incita-nos a compor novos campos de problematização - atentos a outras perspectivas de posicionamento sobre as políticas de formação humana em nosso tempo.

O contexto da prova de Filosofia da escola de Taguatinga expõe em seus limites nossa dificuldade em definir critérios para a seleção dos conhecimentos a serem ensinados. Sem a pretensão de imaginar formas de conhecimento privilegiadas, poderíamos refletir sobre os modos de ancoragem social dos conteúdos que ensinamos (MOREIRA; CANDAU, 2008).

Os discursos pedagógicos progressivistas, associados aos direcionamentos recentes dos organismos multilaterais, levam-nos a pensar que uma escola atraente é aquela centrada nas experiências culturais e/ou nos interesses individuais dos estudantes, assim como em suas possibilidades de intervenção no mundo da economia (KRAWCZYK, 2014). Levando essa perspectiva ao extremo, tal como realiza Young (2011), parece que nossa pauta da escolarização tem se distanciado da questão objetiva do conhecimento escolar ${ }^{2}$. A questão de prova que trata de uma letra de funk, com a qual iniciamos nossa abordagem, não se apresenta

\footnotetext{
${ }^{2}$ A referida questão tem recebido um conjunto de investimentos analíticos no âmbito da sociologia do currículo, em diferentes contextos, priorizando examinar sua dimensão "inescapável" para o exame das políticas de escolarização contemporâneas (TURNER, 2012; MOORE, 2012).
} 
como um problema, apenas expõe uma cultura escolar em deslocamento (MARRERO, 2012; TIRAMONTI, 2011), uma escola em crise na sua institucionalidade (DUBET, 2010) ou ainda um currículo escolar demarcado por "dispositivos de customização" (SILVA, 2014).

Cabe reiterar ainda que, contextualmente, nossas experiências têm sido fabricadas em uma "cultura do novo capitalismo", tal como nomeia os cenários contemporâneos o sociólogo Richard Sennett (2008). Segundo o referido sociólogo, com o advento das novas formas do capitalismo, os modos pelos quais os sujeitos são produzidos e as instituições são organizadas ingressaram em um intenso processo de deslocamento. As instituições sociais, diferentemente do período caracterizado como capitalismo industrial, não mais se assemelham a uma jaula de ferro, mas se aproximam da forma de um aparelho de MP3. Da estabilidade institucional, migramos para modelos flexíveis, interativos e multidimensionais. Sob tais condições, os próprios sujeitos passam a ter sua conduta regulada por outros princípios: planejam uma vida em curto prazo, em contextos vulneráveis, marcados pela ansiedade, pelo fantasma da inutilidade ou ainda pela meritocracia. As condições políticas de nosso tempo, conforme a abordagem sennettiana, assinalam a primazia da meritocracia como modo de gestão de nossas vidas (SENNETT, 2008). Essas condições caracterizam (e moldam) as políticas curriculares para nosso tempo, assim como enfatizam a busca de capacitações e inovações permanentes para a organização curricular do Ensino Médio (SILVA, 2014).

Considerando tais problemáticas, examinaremos as políticas contemporâneas de integração curricular para o Ensino Médio, produzindo um campo de problematização acerca das noções de conhecimento escolar mobilizadas em nosso tempo. Assim sendo, organizamos o presente texto em três partes. Na primeira, revisaremos as concepções atuais sobre o conhecimento escolar, contextualizando-as no cenário de crise de sentido da instituição escolar. Na segunda seção, em um mapeamento dos textos curriculares, apresentaremos as possibilidades de entendimento sobre a integração curricular no Ensino Médio, tal como são evidenciadas nos documentos orientadores dessas políticas. Por fim, na terceira seção, esboçaremos algumas impressões empíricas em torno do Programa Ensino Médio Inovador, buscando perceber as possibilidades de gestão e organização do conhecimento escolar em seus Projetos de Redesenho Curricular (PRC).

\section{POLÍTICAS DE CONSTITUIÇÃO DO CONHECIMENTO ESCOLAR: UMA REVISÃO}

Para posicionarmos o presente estudo no âmbito das políticas de currículo, nesse momento daremos um passo adiante para estudarmos um dos principais conceitos desse campo analítico - o do conhecimento escolar. Inspirada em autores do campo da sociologia do currículo, há mais de uma década, Santos (1995) realizou uma pesquisa acerca dos processos de produção do conhecimento escolar, em suas interfaces com a didática. Inicialmente, a pesquisadora brasileira sugeria o argumento de que o conhecimento escolar apresentava características específicas, diferenciando-se de outras formas de conhecimento.

\begin{tabular}{l|l|l|l|l|l|l|} 
(C) ETD - Educ. temat. digit. & Campinas, SP & v.17 & n. 2 & p.252-270 & maio/ago. 2015 & ISSN 1676-2592 \\
\hline
\end{tabular} 
Em sua leitura, "o sistema escolar e o contexto econômico e social que o informam, com base nas diferentes relações de poder que se estabelecem no interior do aparelho escolar e entre este e a sociedade, produzem o que chamamos de conhecimento escolar" (SANTOS, 1995, p. 27).

A produção do conhecimento escolar, desde esse entendimento, alarga o espaço de intervenção sobre as práticas pedagógicas para além do debate entre conteúdos e métodos. O conhecimento pode ser compreendido como uma construção social.

Santos (1995) discute que o conhecimento escolar, pelo menos desde Bernstein e Bourdieu, apresenta-se como um objeto de estudo da sociologia do currículo. Entretanto, ainda que examinado em perspectiva crítica, a autora indica a ausência de trabalhos mais sistemáticos sobre o referido objeto. Valendo-se de um estudo de Philip Wexler, a pesquisadora propõe a metáfora da montagem social como explicativa para o processo de fabricação do conhecimento escolar. "O conhecimento, nessa visão, não seria o resultado do trabalho individual do autor, mas o resultado de uma prática coletiva envolvendo uma série de ações transformadoras que resultariam em um novo produto" (SANTOS, 1995, p. 30).

O estudo citado favoreceu o entendimento do conhecimento escolar como uma elaboração que se dá no plano social, afastando-se dos argumentos de que se tratava de uma simplificação dos conhecimentos científicos. Servindo-se desse campo teórico, mas propondo outros delineamentos, Moreira (2007) ocupou-se de um estudo sobre o conhecimento escolar em propostas curriculares alternativas, implementadas no Brasil a partir da década de 1990. Ao examinar criticamente a proposta curricular da Escola Plural, implementada há mais de uma década pela rede municipal de Belo Horizonte, Moreira argumenta que tais estratégias curriculares "podem, paradoxalmente, criar um espaço discursivo no qual se 'segregam' as crianças das camadas populares, reduzindo suas possibilidades de autonomia na sociedade, frente às crianças dos grupos privilegiados" (2007, p. 266-267).

Mesmo que a Escola Plural tenha sido produzida após os movimentos de renovação pedagógica dos anos 1990, e seja inspirada por ideais progressivistas, Moreira encaminha que "no processo de construção curricular, os focos na criança e na cultura, ainda que indispensáveis, são insuficientes" (2007, p. 286). O pesquisador defende ainda que a essas preocupações seja associada uma preocupação com o conhecimento. Em suas palavras, "não basta procurar desenvolver no aluno uma autoimagem positiva. Não basta organizar-lhe um espaço para convivência, socialização e aprendizado de valores e condutas. Não basta a sensibilidade com a totalidade da formação humana. Não basta clamar pelo direito de todos os estudantes à realização plena como sujeitos socioculturais. Se tudo isso é indispensável, não é suficiente" (MOREIRA, 2007, p. 287). Nessa direção, Moreira defende a retomada do conhecimento escolar como categoria fundamental para o estudo contemporâneo das políticas de currículo (MOREIRA, 2013). 
Para este texto, reconhecemos ainda que, em uma abordagem contemporânea, torna-se possível reconhecer as articulações existentes entre as políticas de escolarização e o contexto econômico mais amplo. Sob as conhecidas condições da globalização, do neoliberalismo e da consequente exacerbação da competitividade, o campo de seleção e definição dos conhecimentos escolares é ressignificado, sendo posicionado em outras lógicas (SILVA, 2014). Nessa direção, um dos conceitos utilizados com maior recorrência nas pesquisas sobre as políticas curriculares é o de performatividade, mobilizado intensamente pelo sociólogo Stephen Ball (2010), ao longo da última década. O uso produtivo dessa noção tem sido relevante para pesquisas tanto na área da educação, quanto no estudo das políticas sociais. Partindo de um diagnóstico publicado em 1979, pelo filósofo Jean-François Lyotard, Ball posiciona a performatividade como "uma tecnologia, uma cultura e um modo de regulação" (BALL, 2010, p. 38). Desse posicionamento teórico, deriva-se um novo entendimento acerca das políticas contemporâneas, pela emergência e consolidação de novas relações de poder, materializadas em "um discurso no qual emerge uma nova forma de legitimação nas sociedades pós-industriais para a produção do conhecimento e sua transmissão por meio da educação" (BALL, 2010, p. 38). Ao examinar esse contexto, Ball sugere que tais relações de poder favorecem o desenvolvimento de novas regulações da subjetividade, esboçando novas identidades sociais e outras formas de vida regidas pelos valores da competição, da intensificação e da qualidade.

A mobilização dessas formas de regulação social, ainda na leitura proposta por Ball (2010), aproxima-se do deslocamento analítico proposto por Deleuze no início dos anos 1990 - "das sociedades disciplinares para as de controle" (DELEUZE, 1992). Os modos de regulação, então, não seriam mais da ordem da vigilância; mas, dar-se-iam por meio de um conjunto de demandas e expectativas flexíveis, variáveis de acordo com os indicadores fabricados por diversas organizações. As subjetividades que emergem desse jogo de relações tendem a projetar, por exemplo, um novo tipo de professor. Os sujeitos colocam em ação seus interesses (materiais e pessoais) na direção de competir por recursos e intensificar suas formas de trabalho (BALL, 2010). "O ponto aqui é primariamente sobre a performance em si mesma, como um sistema de medidas e indicadores (signos) e jogos de relações, mais do que sobre suas funções para o sistema social e para a economia" (BALL, 2010, p. 41). Em outras palavras, derivadas de determinadas relações sociais (que primam pela responsabilização e pelo empreendedorismo), os indivíduos fabricam suas subjetividades, objetivando tornaremse mais competitivos nas tramas desse arranjo capitalista (SILVA, 2013).

A busca pela competitividade delineia novos percursos formativos, mais flexíveis e eficientes. Cabe reiterar, porém, que os próprios indivíduos desejam mobilizar suas vidas sob esses valores. Especificamente, a mobilização desses valores formativos associa-se ao desejo dos próprios indivíduos em intensificarem suas formas competitivas. Na acepção de Ball, "nós nos tornamos fáceis de usar; nós nos tornamos parte da economia do conhecimento. Nós aprendemos que nós podemos ser mais do que já fomos. Existe algo muito sedutor em ser 
adequadamente apaixonado pela excelência, em conquistar o pico da performance" (BALL, 2010, p. 45).

Cabe reiterar nesse momento, então, que os próprios sujeitos aspiram ingressar no jogo competitivo da busca pelo "pico da performance". Tais relações, portanto, não são verticais, nem violentas -, mas, antes disso, sedutoras. Nessas fabricações individuais, as performances são gerenciadas em seus detalhes, almejando a qualificação e a diferenciação das condutas. Ainda conforme Ball, a disseminação desses valores conduz a constituição de uma sociedade performativa, na qual a base é "a disseminação da forma de mercado ou empresarial como narrativa-mestra que define e confina toda a variedade de relações dentro do Estado e entre o Estado, a sociedade civil e a economia" (BALL, 2010, p. 50). Sob essa argumentação, o valor que rege as relações sociais do nosso tempo tem a forma da "empresa", tal como o diagnóstico deleuziano já referido (DELEUZE, 1992).

Lima (2012), em uma análise crítica da sociedade atual, argumenta que as políticas e práticas de escolarização têm sido conduzidas pelo lema "aprender para ganhar, conhecer para competir". Em sua abordagem, a partir das condições contemporâneas da sociedade de aprendizagem, os sujeitos são conduzidos a melhorar seus desempenhos visando a atender "aos imperativos de eficácia e eficiência, de inovação e de competitividade, impostos por uma sociedade cada vez mais complexa" (LIMA, 2012, p. 16). Esse ideário pedagógico tem emergido nas diferentes reformas educacionais, impulsionado tanto por discursos do âmbito empresarial, quanto pelos direcionamentos de importantes organizações internacionais. Uma das nuances desse processo, exploradas pelo sociólogo português, refere-se a uma crença no "potencial mítico" da educação, supondo que ela seja capaz de resolver todos os problemas de nossa sociedade. Ao mesmo tempo, faz-se possível perceber que os objetivos da escolarização são reduzidos à esfera econômica, possibilitando a emergência de paradigmas formativos centrados na competitividade, na inovação e na qualificação para o mercado de trabalho. Assim, a própria concepção de conhecimento altera seu estatuto.

Sob tais condições, a educação é dimensionada em uma visão focalista, na qual a competitividade e a empregabilidade passam a ocupar a centralidade explicativa para a organização da vida escolar. Uma nova gramática orienta a composição dos currículos, uma vez que "a ideia de escolha de oportunidades de aprendizagem passou a ser central, fruto de estratégias e racionalidades individuais, típicas de clientes e de consumidores" (LIMA, 2012, p. 33). O trabalho desenvolvido pelas instituições educacionais, sob a égide de uma gestão performativa (BALL, 2004), desloca-se para uma lógica produtora de novos perfis, esboçados pela busca de resultados, desempenho e qualificação. Segundo Ball, as próprias práticas de ensino são ressignificadas, "reelaboradas e reduzidas a seguir regras geradas de modo exógeno e a atingir metas" (BALL, 2004, p. 1117).

Referindo-se ao contexto brasileiro, Libâneo (2012) sugere que se faz necessário ultrapassar os limites de uma concepção instrumental de conhecimento e da redução da escolarização a aprendizagens mínimas. Inspirado pelos estudos de Vygotsky, o pesquisador 
brasileiro revitaliza a perspectiva de que "o papel da escola é prover aos alunos a apropriação de ciência e da cultura acumuladas historicamente, como condição para seu desenvolvimento cognitivo, afetivo e moral e torná-los aptos à reorganização crítica de tal cultura" (LIBÂNEO, 2012, p. 25-26). Em outras palavras, a escola torna-se uma ferramenta para a democracia e para a inclusão social quando coloca a aprendizagem no centro do processo formativo dela. $\mathrm{O}$ desafio posto, nessa leitura, está na garantia da formação cultural e científica dos estudantes, ao mesmo tempo em que suas experiências culturais sejam levadas em consideração. Ou ainda, "não há justiça social sem conhecimento; não há cidadania se os alunos não aprenderem" (LIBÂNEO, 2012, p. 26). Essa consideração nos direciona ao argumento proposto por Lima (2012), no qual a educação é mais que uma questão econômica. Assim, não poderíamos reduzir nosso compromisso pedagógico aos limites de uma sociedade que visa a "aprender para ganhar e conhecer para competir".

Assim sendo, indicamos que, ao inscrever-se no campo dos Estudos Curriculares, o presente estudo privilegia examinar as concepções de conhecimento escolar emergentes dos projetos de redesenho curricular produzidos no âmbito do programa Ensino Médio Inovador, ao mesmo tempo em que intencionamos examinar as interfaces entre as políticas curriculares contemporâneas e as demandas advindas da cultura do novo capitalismo (SENNETT, 2008). A opção por tal campo teórico decorre de nossa trajetória investigativa, na qual temos realizado um conjunto de produções científicas em torno do currículo e do conhecimento escolar. Especificamente para este estudo orientaremos nossa abordagem para uma revisão dos sentidos de conhecimento escolar emergentes nos documentos curriculares para o Ensino Médio, tomando como foco analítico as estratégias de integração curricular. A seguir apresentaremos os aportes epistemológicos e os procedimentos metodológicos que orientam nossas incursões empíricas.

\section{PARA A ANÁliSE DOS TEXTOS CURRICULARES: APORTES METODOLÓGICOS}

Considerando os pressupostos teóricos, anteriormente apresentados, nesta seção destacaremos os procedimentos analíticos utilizados na investigação da qual este artigo deriva. De imediato assinalamos que o estudo caracteriza-se como uma abordagem qualitativa (CRESWELL, 2010). Entre outras caracterizações possíveis, tal abordagem pode ser delineada pela presença/atuação do pesquisador como instrumento fundamental, pela análise de dados indutiva, pelo uso de lentes teóricas ou por instrumentos interpretativos (CRESWELL, 2010). Dos inúmeros procedimentos, típicos de uma abordagem qualitativa, escolhemos para nossa investigação a análise documental. Assim sendo, organizamos a presente intervenção investigativa em três etapas, sumarizadas a seguir. 
Na primeira etapa, inicialmente realizamos uma revisão da literatura da temática do estudo (SILVA; PEREIRA, 2013). Buscamos em diferentes bases de dados brasileiras sistematizar as principais tendências teóricas e empíricas para o tratamento analítico das políticas do conhecimento escolar. Ao mesmo tempo, desencadeamos uma revisão conceitual da temática em diferentes tradições investigativas dos Estudos Curriculares. Tomando como base esse levantamento, realizamos a seleção dos documentos a serem investigados. Para a seleção operamos com os seguintes critérios: a) etapa da educação básica a que se destina; b) período de publicação; c) repercussão nas políticas de currículo do Ensino Médio; d) articulação aos documentos publicados pelo Ministério da Educação e pelos organismos internacionais.

$\mathrm{Na}$ segunda etapa, delineamos, em um momento preliminar, as técnicas para a coleta e análise de dados. Como indicamos anteriormente, realizamos uma análise documental, optando pelo tratamento analítico dos materiais coletados a partir da análise das concepções de conhecimento escolar dela emergentes. A análise de documentos, de acordo com Cellard (2012), favorece uma leitura das políticas e práticas investigadas, na medida em que "o documento permite acrescentar a dimensão do tempo à compreensão do social" (p. 295). Concomitantemente, vale indicar que a referida modalidade de análise apresenta limites e potencialidades. Segundo Creswell (2010), seriam limites deste tipo de estudo a pouca interação com os sujeitos sociais, a possibilidade de os documentos estarem incompletos ou mesmo a elaboração de uma leitura descontextualizada. Suas potencialidades estariam vinculadas ao uso de dados criteriosos e confiáveis, à economia de tempo na transcrição das informações e à facilidade do acesso aos dados (CRESWELL, 2010).

Para a seleção dos documentos, mobilizamos quatro indicadores para a compilação do material analítico, a saber: autenticidade, credibilidade, representatividade e significação (FLICK, 2009). Associado a esses indicadores, produzimos dois recortes: um temporal e outro político. No que tange ao critério temporal, selecionamos documentos produzidos no período posterior ao ano de 1996, ano da publicação da Lei de Diretrizes e Bases da Educação Nacional. No que tange ao critério político, optamos por documentos produzidos em diferentes âmbitos de gestão das políticas curriculares - desde as organizações internacionais até aqueles produzidos nos Estados da Região Sul do Brasil. Com isso, pretendemos nos distanciar de determinadas dicotomias, tais como entre políticas macro e micro, ou entre local e global, comuns nas pesquisas curriculares.

Com esses critérios compomos um corpus documental que teve como objetivo "ter uma amostra representativa de todos os documentos de um determinado tipo" (FLICK, 2009, p. 234). Da mesma forma, vale assinalar que não compreendemos os documentos como fontes de verdades previamente estabelecidas, mas como campos a serem problematizados pelas suas dimensões contextuais e modos de abordagem. Assim, entendemos que "os documentos representam uma versão específica de realidades construídas para objetivos específicos" (FLICK, 2009, p. 234). Tomando tais considerações, compomos o seguinte 
corpus documental (para fins deste artigo, atribuímos centralidade aos documentos publicados pelo Estado Brasileiro).

Quadro 1 - Documentos pré-selecionados para a análise

\begin{tabular}{l|l|l}
\hline Título do documento & Ano & Contexto de elaboração \\
\hline Protótipos curriculares de Ensino Médio e Ensino Médio & 2011 & Unesco \\
Integrado & 2008 & Unesco \\
Reforma da educação secundária & 2003 & Unesco \\
A ciência para o século XXI & 2010 & Brasil \\
Diretrizes curriculares nacionais para a EB & 2012 & Brasil \\
Diretrizes curriculares nacionais para o EM & 2011 & Rio Grande do Sul \\
Ensino Médio Politécnico & 2012 & Rio Grande do Sul \\
Programa Ensino Médio Inovador: documento orientador & 2013 & Brasil \\
Resolução/CD/FNDE n. 31 22 de julho de 2013 & 2013 & Brasil \\
Proposta de atividades com vistas ao percurso de redesenho & 2013 & Paraná \\
curricular & & \\
Orientação pedagógica para adesão e elaboração do PRC no & 2013 & Paraná \\
Paraná & & \\
\hline
\end{tabular}

Fonte: Pesquisa do autor

A seguir, para o exame dos documentos, realizamos inúmeras leituras e sistematizações dos materiais selecionados, objetivando mapear suas recorrências, ligações e configurações significativas. De acordo com Cellard (2012), esse procedimento produz um tipo de "reconstrução".

A fim de estabelecer essas ligações e de constituir configurações significativas é importante extrair os elementos pertinentes do texto, compará-los com outros elementos contidos no corpus documental. A maioria dos metodologistas concorda em dizer que é a leitura repetida que permite, finalmente, tomar consciência das similitudes, relações e diferenças capazes de levar a uma reconstrução admissível e confiável. As combinações possíveis entre os diferentes elementos contidos nas fontes estabelecem-se em relação ao contexto, à problemática, ou ao quadro histórico, mas também, deve-se admiti-lo, em função da própria personalidade do pesquisador, de sua posição teórica ou ideológica (CELLARD, 2012, p. 304).

Do ponto de vista operacional, procuramos dimensionar os documentos a partir de seus contextos de elaboração, descrevendo os cenários políticos e econômicos de sua publicação. Tal preocupação nos conduziu a perceber os documentos como possibilidades de contextualização e caracterização das políticas de um determinado tempo. Conforme Flick (2009), essa precaução nos permite perceber tais fontes não como "contêineres de informação", mas "vistos e analisados como dispositivos comunicativos metodologicamente desenvolvidos na construção de versões sobre eventos" (p. 234, grifos do autor).

Para finalizar a descrição de nossa abordagem investigativa, importa assinalar ainda que, na análise documental que estamos desenvolvendo (a pesquisa está em andamento), procuramos diversificar as fontes, cotejando-as entre si e produzindo leituras de suas condições exteriores. De acordo com Cellard (2012), "uma análise confiável tenta cercar a questão, recorrendo a elementos provenientes, tanto quanto possível, de fontes, pessoas ou 
grupos representando muitos interesses diferentes, de modo a obter um ponto de vista tão global e diversificado quanto pode ser" (p. 305). Para além dessa perspectiva de ampliação das formas de análise, procuramos potencializar diferentes pistas teóricas, advindas de nossos pressupostos, visando um mapeamento das concepções de conhecimento escolar emergentes do processo de implementação do Programa Ensino Médio Inovador. A seguir descrevemos os resultados parciais de uma de nossas análises documentais, vislumbrando nossas perspectivas em torno do conhecimento escolar no Ensino Médio.

\section{A INTEGRAÇÃO CURRICULAR NAS POLÍTICAS BRASILEIRAS DA ATUALIDADE: APROXIMAÇÕES}

Quando examinamos os currículos escolares, em uma perspectiva histórica, notamos que o incentivo às práticas de integração curricular tem sido intenso e diversificado (LOPES; MACEDO, 2011). Pelo menos no Brasil, desde a primeira metade do século XX, encontramos noções como "projetos", "centros de interesse" e "ensino globalizado", em perspectivas teóricas diferentes, que desde cedo assinalavam a importância desse processo ${ }^{3}$. Entretanto, será no final do século que encontraremos um movimento mais sistemático na direção da interdisciplinaridade, tanto no aspecto epistemológico, quanto no pedagógico (VEIGA-NETO, 2012). Os documentos curriculares brasileiros, a partir desse período, começaram a multiplicar as possibilidades organizativas da integração curricular, valendo-se de expressões que adquiriram grande popularidade entre os professores tais como: interdisciplinaridade, transversalidade, contextualização, pluridisciplinaridade e até multirreferencialidade. Em comum a essas abordagens encontramos uma crítica aos modelos conservadores e/ou disciplinares de seleção e organização dos conhecimentos a serem ensinados (LOPES; MACEDO, 2011).

No que tange às atuais políticas curriculares para o Ensino Médio, em nosso país, notamos uma intensificação dos investimentos nessa direção. Na medida em que se ampliam as intencionalidades democratizadoras dessa etapa da Educação Básica, entende-se que há uma necessidade de atualizar sua agenda formativa, adequando-a às demandas da sociedade e da economia contemporâneas e, ao mesmo tempo, tornando-a mais atraente aos jovens do século XXI. Sob tais argumentos, encontramos formas diversas de organizar a integração curricular, ora enfatizando as culturas e os interesses dos jovens, ora privilegiando uma interlocução com as questões advindas do mercado de trabalho, ao requerer novas habilidades e competências formativas. A seguir, examinaremos alguns sentidos que são apresentados em textos curriculares recentemente publicados pelo Ministério da Educação.

\footnotetext{
${ }^{3}$ Para o exame das políticas de integração curricular, no contexto brasileiro, uma das sistematizações mais relevantes encontramos em Lopes (2008).
} 
Ao revisarmos, inicialmente, as Diretrizes Curriculares Nacionais para o Ensino Médio, materializadas na Resolução CNE n. 2 de 30 de janeiro de 2012, encontramos importantes pistas para o delineamento das políticas de integração curricular destinadas a esta etapa da Educação Básica. No artigo $5^{\circ}$, no qual são apresentados os pressupostos basilares que orientam a oferta e a organização do Ensino Médio, encontramos pelo menos dois princípios que versam sobre a temática em exame. O primeiro sentido, expresso no item IV, remete à integração entre conhecimentos gerais e técnico-profissionais, a ser realizada pela contextualização e interdisciplinaridade. Outro sentido, afirmado no item VIII, evidencia-se na aproximação entre a educação e as dimensões do trabalho, da cultura, da ciência e da tecnologia, tomada na qualidade de aporte central para o desenvolvimento curricular.

A perspectiva da integração curricular adquire visibilidade e centralidade na própria conceituação de currículo, apresentada no artigo $6^{\circ}$ do referido texto curricular.

Art. $6^{\circ}$ - O currículo é conceituado como a proposta de ação constituída pela seleção de conhecimentos construídos pela sociedade, expressando-se por práticas escolares que se desdobram em torno de conhecimentos escolares relevantes, permeadas pelas relações sociais, articulando vivências e saberes dos estudantes e contribuindo para o desenvolvimento de suas identidades e condições cognitivas e socio-afetivas (BRASIL, 2012, grifo nosso).

Considerando essa definição, as Diretrizes Curriculares ainda assinalam a necessária aproximação entre a base nacional comum e a parte diversificada, de modo que não se constituam em 'blocos distintos'. A partir disso, encaminha a organização dos currículos do Ensino Médio em áreas do conhecimento, a saber: Linguagens; Matemática; Ciências da Natureza e Ciências Humanas. Tal forma organizativa sugere o favorecimento de atividades interdisciplinares e contextualizadas que produzam novas formas de articulação entre os saberes. Entretanto, o mesmo artigo, em seu segundo parágrafo, faz uma importante observação e apresenta outro direcionamento para a questão da integração.

\footnotetext{
"A organização por áreas de conhecimento não dilui nem exclui componentes curriculares com especificidades e saberes próprios construídos e sistematizados, mas implica no fortalecimento das relações entre eles e a sua contextualização para apreensão e intervenção na realidade, requerendo planejamento e execução conjugados e operativos dos seus professores" (BRASIL, 2012).
}

Nessa direção, o referido texto curricular ainda apresenta uma relação de cinco temas a serem trabalhados, obrigatoriamente (artigo 10), de forma transversal e integradamente: educação alimentar e nutricional; respeito e valorização do idoso; educação ambiental; educação para o trânsito e educação em direitos humanos. Em uma leitura diagonal das Diretrizes Curriculares, notamos uma ênfase significativa de processos de integração curricular expressos na articulação entre saberes, entre dimensões formativas ou entre temas transversais. $\mathrm{O}$ eixo articulador entre tais possibilidades evidencia-se na perspectiva da pesquisa como princípio pedagógico. Ainda conforme o documento, esse princípio mobilizase "possibilitando que o estudante possa ser protagonista na investigação e na busca de 
respostas em um processo autônomo de (re)construção de conhecimentos" (BRASIL, 2012, artigo 13).

$\mathrm{Na}$ busca por um mapeamento dos sentidos contemporâneos atribuídos às políticas de integração curricular, também realizamos uma análise de alguns materiais vinculados ao recente Pacto Nacional pelo Fortalecimento do Ensino Médio, criado pelo Ministério da Educação por meio da Portaria n. 1.140, de 22 de novembro de 2013 (BRASIL, 2013b). Instituído pelo Ministério em parceria com as secretarias estaduais de educação, a ação de governo enfatiza a valorização e a formação continuada dos profissionais que atuam no Ensino Médio nas redes públicas de ensino. Por conta de bolsas de estudo e de pesquisa, tais profissionais participam de cursos promovidos pelas universidades públicas do País. Com foco nos currículos escolares do Ensino Médio, desencadeando práticas na perspectiva da "formação humana integral", os cursos direcionados aos professores iniciaram em fevereiro deste ano.

Entre os materiais que subsidiam a formação continuada, encontramos o Caderno IV - da primeira etapa -, que apresenta os tópicos referentes às áreas do conhecimento e à integração curricular (BRASIL, 2014). Em aproximação aos documentos anteriormente examinados, defende-se a promoção de currículos integrados, que sejam contextualizados tanto historicamente, quanto nas condições contemporâneas. Sob esse pressuposto, os conteúdos a serem ensinados são posicionados em condições sociais específicas, distanciando-se de entendimentos vinculados a teorias ou conceitos abstratos. O currículo integrado, descrito no caderno IV do Pacto, indica que os conteúdos escolares sejam percebidos em uma relação de totalidade, uma vez que são delineados "pelas relações que os homens constroem entre si" (BRASIL, 2014, p. 26).

$\mathrm{Na}$ acepção proposta, o método de ensino ocupa um lugar importante, visto que "deve restabelecer as relações dinâmicas e dialéticas entre os conceitos, reconstituindo aquelas que configuram a totalidade concreta da qual se originaram, de modo que o objeto a ser conhecido revele-se gradativamente em suas peculiaridades próprias" (BRASIL, 2014, p. 26). A integração curricular, a partir dessa argumentação, é definida pela "reconstrução da totalidade pela relação entre os conceitos originados a partir de distintos recortes da realidade" (BRASIL, 2014, p. 26). Assim sendo, no presente documento, notamos uma ênfase nas relações dialéticas entre conceitos e práticas concretas, nos quais a integração curricular é definida pela possibilidade de os sujeitos compreenderem o processo social e histórico que conforma suas existências, ao mesmo tempo em que reconhece o conhecimento como uma construção a ser contextualizada metodologicamente.

Ao examinarmos os referidos documentos, percebemos que a integração curricular apresenta-se como uma prática central no contexto recente do Ensino Médio no Brasil. Porém, constatamos uma pulverização discursiva em torno do conceito, ora associando-o a temas transversais, ora dimensionando-o em justaposição à totalidade. Para além dessa questão, bastante relevante, temos defendido que as políticas de integração curricular 
adquirem potencialidade formativa, quanto mais estiverem aproximadas à seleção de conhecimentos escolares relevantes (SILVA; PEREIRA, 2013). Ampliando essa perspectiva, a seguir indicaremos os pressupostos e procedimentos concernentes à nossa abordagem analítica, para estabelecermos como foco o programa Ensino Médio Inovador.

\section{O PROGRAMA ENSINO MÉDIO INOVADOR EM PERSPECTIVA}

Conforme argumentamos inicialmente, ao longo das últimas décadas, as políticas curriculares têm sido alvo de um conjunto de reformas (KRAWCZYK, 2012). Por diferentes racionalidades políticas e econômicas, em diferentes países notamos um intenso investimento nas políticas curriculares para a Educação Básica, favorecendo a constituição daquilo que Dale (2004) nomeia como "agenda globalmente estruturada". Entre aquelas que receberam maior evidência nos últimos anos, podemos destacar as que dizem respeito ao Ensino Médio, por causa de suas aproximações com os processos de educação profissional ou mesmo de acesso à universidade. Escolhemos tomar como foco analítico para este texto, conforme assinalamos anteriormente, as políticas de integração curricular que são mobilizadas em um desses programas recentemente implementados pelo Ministério da Educação de nosso País, o programa Ensino Médio Inovador (PROEMI).

$\mathrm{Na}$ Contemporaneidade temos notado um intenso investimento político nas políticas curriculares para o Ensino Médio. Para fins dessa composição analítica, valeria a pena assinalar, por exemplo, a Emenda Constitucional n. 59 que legisla sobre a obrigatoriedade do ensino escolar dos 4 aos 17 anos de idade ou ainda a meta três do novo Plano Nacional de Educação que indica a universalização do acesso ao Ensino Médio na próxima década. $\mathrm{Na}$ mesma direção desses esforços, encontramos o Programa Ensino Médio Inovador (PROEMI), criado pela Portaria n. 971 do ano de 2009 e direcionado para efetivar um debate sobre o Ensino Médio nos diferentes sistemas de ensino. Com o referido programa, o Ministério da Educação visa fomentar estratégias curriculares inovadoras, pela disponibilização de apoio técnico e financeiro. Articula-se a essa dimensão a busca pela "disseminação da cultura de um currículo dinâmico, flexível e compatível com as exigências da sociedade contemporânea" (BRASIL, 2013a, p. 11).

Politicamente, privilegia-se a elaboração de estratégias que garantam a oferta de um Ensino Médio de qualidade para todos. Enquanto um programa indutor, o PROEMI é integrante do Plano de Desenvolvimento da Educação (PDE) e visa a "induzir o redesenho dos currículos do Ensino Médio, compreendendo que as ações propostas inicialmente vão sendo incorporadas ao currículo, ampliando o tempo na escola e a diversidade de práticas pedagógicas, atendendo às necessidades e expectativas dos estudantes do ensino médio" (BRASIL, 2013a, p. 10). O Documento Orientador, do referido programa, informa que sua atuação dar-se-á pela cooperação entre os entes federados, sendo atribuição do Ministério da Educação os apoios técnico e financeiro. "O apoio técnico-financeiro será destinado por quatro anos para que as escolas de cada estado realizem seu redesenho curricular, prevendo 
que nos três primeiros anos a escola promoverá a discussão e a elaboração gradativa de um novo currículo e o quarto ano será destinado a sua consolidação" (BRASIL, 2013a, p. 11).

As ferramentas que organizam e sistematizam as propostas de mudanças elaboradas pelas escolas para seus currículos são os "projetos de redesenho curricular" (PRC). Ao partirem das condições das instituições escolares, os projetos devem ter como foco a "promoção de melhorias significativas para a aprendizagem do estudante, reconhecendo as especificidades regionais e as concepções curriculares implementadas pelas redes de ensino" (BRASIL, 2013a, p. 11). Para a operacionalização do referido redesenho curricular, o Documento Base do PROEMI (BRASIL, 2009) indica alguns elementos básicos, a saber: a ampliação da carga horária para um mínimo de 3 mil horas, o foco na leitura e no letramento, atividades de iniciação científica, atividades em línguas estrangeiras, fomento à produção artística, comunicação e cultura digital, oferta de atividades optativas, estimulo à participação no ENEM, entre outras.

Para a implementação de seu Projeto de Redesenho Curricular, as escolas poderão diversificar seus formatos de atividades por meio de "disciplinas optativas, oficinas, clubes de interesse, seminários integrados, grupos de pesquisa, trabalhos de campo e demais ações interdisciplinares" (BRASIL, 2013a, p. 14). Em seu PRC as instituições poderão adquirir os materiais necessários, bem como contratar formação para seus profissionais. Para o preenchimento do PRC na plataforma específica desenvolvida pelo Ministério, deverão ser indicados os macrocampos organizadores das atividades, conforme o quadro abaixo:

Quadro 2 - Macrocampos do PROEMI

Macrocampos obrigatórios

Macrocampos eletivos
Integração curricular

Leitura e letramento

Iniciação científica e pesquisa

Línguas estrangeiras

Cultura corporal

Produção e fruição das artes

Comunicação, cultura digital e uso de mídias

Participação Estudantil

Fonte: Brasil (2013a)

Evidencia-se, ainda, no texto curricular examinado, a necessidade de realizar o referido projeto de forma que as dimensões da ciência, da tecnologia, do trabalho e da cultura sejam contempladas. Também pode ser destacada a ênfase em estratégias de integração curricular, fazendo com que sejam mobilizadas "temáticas diversas por meio do diálogo entre os conteúdos dos diferentes componentes curriculares de uma ou mais áreas do conhecimento" (BRASIL, 2013a, p. 15). Ao mesmo tempo, o Documento Orientador do PROEMI enaltece a relevância dos conhecimentos específicos das diferentes áreas do conhecimento, favorecendo apenas possibilidades que transcendam a fragmentação das disciplinas e dos tempos escolares. Sob essas condições, os macrocampos operariam como eixos organizadores de novos currículos para o Ensino Médio. 
A partir do referido documento, compreende-se como macrocampo "um campo de ação pedagógico-curricular no qual se desenvolvem atividades interativas, integradas e integradoras dos saberes, dos tempos, dos espaços e dos sujeitos envolvidos com a ação educacional" (BRASIL, 2013a, p. 15). A existência desses eixos, em sua concepção, tende a favorecer movimentos de integração curricular. Acompanhando essa perspectiva, cumpre assinalar que o macrocampo obrigatório nomeia-se 'Integração curricular'. Nesse espaço curricular a escola garantirá "diálogo e interação" entre as disciplinas, os tempos, os espaços e os sujeitos - "com vistas a dar maior organicidade ao conjunto de atividades didáticopedagógicas do ensino médio" (BRASIL, 2013a, p. 16). Mais uma vez, reitera-se a busca pela articulação entre as áreas da ciência, da tecnologia, do trabalho e da cultura. $\mathrm{Na}$ acepção proposta pelo Documento orientador, "o currículo integrado em torno do eixo trabalhociência-tecnologia-cultura será capaz de atribuir novos sentidos à escola, dinamizar as experiências oferecidas aos jovens alunos, ressignificar os saberes e as experiências" (BRASIL, 2013a, p. 16).

Notamos, então, que os Projetos de Redesenho Curricular, em sua organização curricular, priorizam atividades que visem à formação de sujeitos protagonistas da produção de seu próprio conhecimento. Indiretamente, nota-se a consolidação de uma pauta formativa para o Ensino Médio que dialoga fortemente com o documento "Protótipos curriculares para o Ensino Médio", publicados pela Unesco no ano de 2011. Intencionando articular os interesses juvenis com a gramática dos "interesses nacionais", o documento referido postula uma definição de currículo "como o conjunto de todas as oportunidades de aprendizagem propiciadas pela escola" (UNESCO, 2011, p. 7). Busca aproximar-se também dos princípios da Lei de Diretrizes e Bases da Educação Brasileira (LDBEN), sobretudo pela vinculação da educação escolar ao mundo do trabalho e à prática social. Entretanto, para atender à LDBEN, opta por tomar como referência os objetos de aprendizagem do novo Exame Nacional do Ensino Médio (ENEM).

Nesse cenário, os protótipos produzidos pela Unesco pretendem operar na interface entre as diretrizes nacionais e os projetos pedagógicos das instituições escolares. $\mathrm{O}$ documento atribui bastante ênfase ao entendimento dos protótipos na qualidade de "referências". Pretende atender tanto às demandas juvenis, quanto às demandas econômicas e políticas para o desenvolvimento nacional. Em articulação com essa perspectiva, como apontamos acima, o currículo é posicionado como um conjunto de oportunidades de aprendizagem. Do ponto de vista pedagógico, os Protótipos Curriculares destacam como base de seus princípios orientadores a formação integral do estudante. "Eles consideram que a continuidade de estudos e a preparação para vida, o exercício da cidadania e o trabalho são demandas dos jovens e finalidades do ensino médio" (UNESCO, 2011, p. 8). Em consonância com isso, supõem que toda atividade curricular terá como centro o desenvolvimento integral do estudante, sobretudo no que se refere a "intervenções transformadoras" na realidade em que o sujeito está inserido. 
$\mathrm{Na}$ medida em que se objetivam práticas que incentivem o protagonismo estudantil, o documento sugere que a pesquisa ocupe o centro do processo de desenvolvimento curricular. "A pesquisa será instrumento de articulação entre o saber acumulado pela humanidade e as propostas de trabalho que estarão no centro do currículo" (UNESCO, 2011, p. 9). Articuladas à noção de pesquisa, estarão as propostas de trabalho individuais e coletivas que cada estudante elaborar e desenvolver. Considerar o Ensino Médio como uma comunidade de aprendizagem é a principal proposição curricular do documento. Ainda que postule a interdisciplinaridade, a contextualização e a produção do currículo por meio de projetos, ou mesmo que sugira a ampliação da carga horária para 3 mil horas, com ampla flexibilização, a produção de uma comunidade de aprendentes é o desafio posto. Diante disso, é feita uma opção metodológica fundamental, a saber: a valorização "das formas didáticas que privilegiam a atividade do estudante no desenvolvimento de suas capacidades e na construção do seu conhecimento" (UNESCO, 2011, p. 14). Tratam-se, pois, de projetos e ações investigativas que desencadeiem o protagonismo dos estudantes, que valorizam as competências genéricas e secundarizam o conhecimento escolar e as diferentes formas de transmissão cultural na escola.

As estratégias políticas que perfazem a constituição da gramática curricular acima evidenciada sugerem que o Ensino Médio seja posicionado como um espaço de formação de personalidades produtivas e direcionado para formas curriculares que estimulem o protagonismo dos jovens. Sob as condições contemporâneas, notamos que essa concepção, ainda que inspirada em uma matriz progressivista, articula-se com as demandas educacionais advindas das tramas do capitalismo contemporâneo, tal como assinalamos desde a primeira seção deste texto. Uma das perspectivas de trabalho escolar que materializa esses princípios pode ser localizada na centralidade da temática da integração curricular na escola brasileira de nosso tempo, enquanto busca a consolidação de currículos flexíveis e interativos, capazes de dialogar com os interesses estudantis e o mundo do trabalho.

Investir, inovar e empreender tornam-se imperativos curriculares do Ensino Médio, mobilizados a partir de duas estratégias distintas e complementares, quais sejam: o desenvolvimento de práticas escolares atraentes e inovadoras e a promoção de oportunidades que possibilitem uma intervenção diferenciada dos sujeitos no mercado de trabalho.

\section{REFERÊNCIAS}

BALL, Stephen. Performatividades e fabricações na economia educacional: rumo a uma sociedade performativa. Educação e Realidade, Porto Alegre, v. 35, n. 2, p. 37-55, maio/ago. 2010. Disponível em: 〈http://goo.gl/onKsRL〉. Acesso em: 04 mai. 2015. ISSN: 2175-6236.

BALL, Stephen. Performatividade, privatização e o Pós-Estado do Bem Estar. Educação e Sociedade, Campinas, SP, v. 25, n. 89, p. 1105-1126, set./dez., 2004. Disponível em: <http://goo.gl/4oiJZw >. Acesso em: 04 mai. 2015. ISSN: 1678-4626. 
BRASIL. Diretrizes curriculares nacionais para o ensino médio. Brasília, DF: MEC, 2012.

BRASIL. Formação de professores do ensino médio - etapa I, caderno IV : áreas de conhecimento e integração curricular. Brasília, DF: MEC; Curitiba: UFPR/Setor de Educação, 2014.

BRASIL. Portaria n. 971, de 9 de outubro de 2009. Institui o Programa Ensino Médio Inovador. Brasília, DF: MEC, 2009.

BRASIL. Programa ensino médio inovador: documento orientador. Brasília, DF: MEC, 2013a.

BRASIL. Portaria n. 1.140 de 22 de novembro de 2013. Institui o Pacto Nacional pelo Fortalecimento do Ensino Médio. Brasília, DF: MEC, 2013 b.

CELLARD, André. A análise documental. In: POUPART, Jean et all. (Orgs.). A pesquisa qualitativa: enfoques epistemológicos e metodológicos. 3.ed. Petrópolis: Vozes, 2012, p. 295-316.

CRESWELL, John. Projeto de pesquisa: métodos qualitativo, quantitativo e misto. 3.ed. Porto Alegre: Artmed, 2010.

DALE, Roger. Globalização e educação: demonstrando a existência de uma "cultura educacional mundial comum" ou "localizando uma "agenda globalmente estruturada para a educação"?. Educação e Sociedade, Campinas, SP, v. 25, n. 87, p. 423-460, maio/ago. 2004. Disponível em: 〈http://goo.gl/QQtxHE>. Acesso em: 04 mai. 2015. ISSN: 1678-4626.

DELEUZE, Gilles. Política. In: DELEUZE, Gilles. Conversações. São Paulo: Ed. 34, 1992, p. 209-226.

DUBET, François. Crisis de la transmisión y declive de la institución. Politica y Sociedad, Madri, v. 47, n. 2, p. 15-25, 2010. Disponível em: 〈http://goo.gl/qyl36I >. Acesso em: 04 mai. 2015. ISSN: 1130-8001.

FLICK, Uwe. Introdução à pesquisa qualitativa. 3.ed. Porto Alegre: Artmed, 2009.

KRAWCZYK, Nora. Ensino Médio: empresários dão as cartas na escola pública. Educação e Sociedade, Campinas, SP, v. 35, n. 126, p. 21-41, jan./mar. 2014. Disponível em: <http://goo.gl/eGFWHg>. Acesso em: 04 mai. 2015. ISSN: 0101-7330.

KRAWCZYK, Nora. Reflexão sobre alguns desafios do Ensino Médio no Brasil hoje. Cadernos de Pesquisa, São Paulo, v. 41, n. 144, p. 752-769, set./dez. 2011. Disponível em: <http://goo.gl/BcmCYp>. Acesso em: 04 mai. 2015. ISSN: 1980-5314.

LIBÂNEO, José Carlos. O dualismo perverso na escola pública brasileira: escola do conhecimento para os ricos, escola do acolhimento social para os pobres. Educação e 
Pesquisa, São Paulo, v. 38, n. 1, p. 13-28, jan./mar. 2012. Disponível em: <http://goo.gl/mesm7A > . Acesso em: 04 mai. 2015. ISSN: 1678-4634.

LIMA, Licínio. Aprender para ganhar, conhecer para competir. São Paulo: Cortez, 2012. LOPES, Alice. Políticas de integração curricular. Rio de Janeiro: EdUERJ, 2008.

LOPES, Alice; MACEDO, Elizabeth. Teorias do currículo. São Paulo: Cortez, 2011.

MARRERO, Adriana. La otra "jaula de hierro": del fatalismo de la exclusion a la recuperación del sentido de lo educativo - una mirada desde la sociología. Sociologias, Porto Alegre, n. 29, p. 128-150, jan./abr. 2012. Disponível em: 〈http://goo.gl/xAsMmJ > . Acesso em: 04 mai. 2015. ISSN: 1807-0337.

MOORE, Rob. Social Realism and the problem of the problem of knowledge in the sociology of education. British Journal of Sociology of Education, London, v. 34, n. 3, p. 1-21, 2012.

MOREIRA, Antônio Flávio; CANDAU, Vera. Indagações sobre currículo: currículo, conhecimento e cultura. Brasília, DF: MEC/SEB, 2008.

MOREIRA, Antônio Flávio. A importância do conhecimento escolar em propostas curriculares alternativas. Educação em Revista, Belo Horizonte, v. 45, p. 265-290, jun. 2007. Disponível em: 〈http://goo.gl/tEX6Ej> . Acesso em: 04 mai. 2015. ISSN: 1892-6621.

MOREIRA, Antonio Flávio Barbosa. Em busca da autonomia docente nas práticas curriculares no Brasil. In: OLIVEIRA, Maria Rita (Org.); PACHECO, José Augusto (Org.). Currículo, didática e formação de professores. Campinas, SP: Papirus, 2013, p. 69-96.

SANTOS, Lucíola. O processo de produção do conhecimento escolar e a didática. In: MOREIRA, Antonio Flávio. Conhecimento educacional e formação do professor. Campinas, SP: Papirus, 1995, p. 27-37.

SENNETT, Richard. A cultura do novo capitalismo. Rio de Janeiro: Record, 2008.

SILVA, Roberto Rafael Dias da. Políticas de escolarização e governamentalidade nas tramas do capitalismo cognitivo: um diagnóstico preliminar. Educação e Pesquisa, São Paulo, v. 39, n. 3, p. 689-704, jul./set. 2013. Disponível em: 〈http://goo.gl/3RCyL4 >. Acesso em: 04 mai. 2015. ISSN: $1678-4634$.

SILVA, Roberto Rafael Dias da; PEREIRA, Anna Luiza Verdi. Políticas de constituição do conhecimento escolar para o Ensino Médio no Rio Grande do Sul: uma analítica de currículo. Educação em Revista, Belo Horizonte, v.30, n.1, p. 127-158, jan. 2014. Disponível em: <http://goo.gl/jIeTzR >. Acesso em: 04 mai. 2015. ISSN: 0102-4698. 
SILVA, Roberto Rafael Dias da; PEREIRA, Anna Luiza Verdi. Políticas de constituição do conhecimento escolar na pesquisa educacional brasileira. Cadernos de Pesquisa, São Paulo, v. 43, n. 150, p. 884-905, set. 2013. Disponível em: 〈http://goo.gl/7NggMr >. Acesso em: 04 mai. 2015. ISSN: 0100-1574.

TIRAMONTI, Guillermina. Educación secundaria argentina: dinámicas de selección y diferenciación. Cadernos de Pesquisa, São Paulo, v. 41, n. 144, p. 692-709, set./dez. 2011. Disponível em: 〈http://goo.gl/7mz8xa $>$. Acesso em: 04 mai. 2015. ISSN: 0100-1574.

TURNER, Stephen. Whatever happened to knowledge? Social Studies of Science, London, v. 42, n. 3, p. 474-480, 2012. Disponível em: 〈http://goo.gl/bcG5dK〉. Acesso em: 04 mai. 2015 .

UNESCO. Protótipos curriculares de Ensino Médio e Ensino Médio Integrado: resumo executivo. Brasília, DF: UNESCO, 2011.

VEIGA-NETO. Alfredo. Currículo e interdisciplinaridade. In: MOREIRA, Antônio Flávio (Org.). Currículo: questões atuais. 18. ed. Campinas, SP: Papirus, 2012, p. 59-102.

YOUNG, Michael. O futuro da educação em uma sociedade do conhecimento: a defesa radical de um currículo disciplinar. Cadernos de Educação, Pelotas, v. 38, p. 395-416, jan./abr. 2011. Disponível em: 〈http://goo.gl/XkYjSj>. Acesso em: 04 mai. 2015. ISSN: 2178-079X.

Como citar este documento:

SILVA, Roberto Rafael Dias da. Políticas de integração curricular para o ensino médio no Brasil contemporâneo: um estudo no programa ensino médio inovador. ETD - Educação Temática Digital, Campinas, SP, v. 17, n. 2, p. 252-270, ago. 2015. ISSN 1676-2592. Disponível em:

<http://periodicos.sbu.unicamp.br/ojs/index.php/etd/article/view/8634854>. Acesso em: 28 ago. 2015. 